\title{
Program Pendampingan Disain Kawasan RTH dan Resapan Air di TPU Muslim Al-lkhlas Kelurahan Sungai Bangkong Kota Pontianak
}

\author{
Zairin Zain*1, Irwin'2, Uray Fery Andi' ${ }^{3}$, Jawas Dwijo Putro ${ }^{4}$ \\ 1,2,3,4Program Studi Arsitektur, Fakultas Teknik, Universitas Tanjungpura \\ *e-mail: zairin.zain@untan.ac.id ${ }^{1}{ }_{2} \underline{\text { irwin@ @civil.untan.ac.id }}^{2}{ }_{2} \underline{\text { urayferyandi@teknik.untan.ac.id }}^{3}$ \\ jawasdwijo@teknik.untan.ac.id ${ }^{4}$
}

\begin{abstract}
TPU Muslim Al-lkhlas in the district of Sungai Bangkong is one of the largest burial ground in Pontianak City, with an area of approximately 4 hectares. The TPU Muslim Al-lkhlas is in the city center, and it requires better management to be able to serve as a Green Open Space (RTH) and a water absorption area in Pontianak City. Regulation of Ministry of Public Works No. 5/2008 concerning Guidelines for Provision and Utilization of Green Open Space in Urban Areas is a reference in the design assistance program for TPU Muslim Al-Ikhlas in the district of Sungai Bangkong as RTH and Water Absorption Areas. The new design of the TPU Muslim Al-Ikhlas is intended to restore the ecological function of the tomb as a water absorption area, a place for the growth of various types of vegetation, generator of microclimate, a place to live birds with social functions of the surrounding community. Careful planning is part of the realization of caring to build a neat and beautiful burial ground with a service of Green Open Space for social and recreational activities and also serves as water absorption areas.
\end{abstract}

Keywords: Design Assistance, Public Burial Ground, Green Open Space, Water Absorption Areas

\begin{abstract}
Abstrak
TPU Muslim Al-lkhlas Kelurahan Sungai Bangkong merupakan salah satu TPU terbesar yang ada di Kota Pontianak dengan lahan seluas kurang lebih 4 Ha. TPU Sungai Bangkong yang berada di pusat kota memerlukan penataan yang lebih baik agar mampu sebagai Ruang Terbuka Hijau dan resapan air Kota Pontianak. Permen Pekerjaan Umum No. 5/2008 tentang Pedoman Penyediaan dan Pemanfaatan Ruang Terbuka Hijau di Kawasan Perkotaan menjadi acuan dalam program pendampingan disain Kawasan TPU Muslim Al lkhlas Kelurahan Sungai Bangkong Sebagai RTH dan Daerah Resapan Air. Penataan Kawasan TPU Muslim Al lkhlas Kelurahan Sungai Bangkong Pontianak dimaksudkan mengembalikan fungsi ekologis makam sebagai daerah resapan air, tempat pertumbuhan berbagai jenis vegetasi, pencipta iklim mikro, tempat hidup burung dan fungsi sosial masyarakat di sekitar. Perencanaan matang menjadi bagian dari perwujudan peduli untuk membangun lingkungan kawasan makam yang tertata rapi dan asri dengan fungsi Ruang Terbuka Hijau untuk aktivitas sosial dan rekreatif serta daerah resapan air.
\end{abstract}

Kata kunci: Pendampingan Disain, Tempat Pemakaman Umum, Ruang Terbuka Hijau, Daerah Resapan Air

\section{PENDAHULUAN}

Keterbatasan lahan perkotaan menuntut adanya penataan ruang penggunaan lahan secara efektif dan efisien. Lahan yang ada merupakan masalah kota-kota besar yang umum di temui di semua kota yang ada, khususnya di Indonesia. Penggunaan tata ruang lahan yang tidak efektif akan berdampak pada penataan ruang-ruang yang lain dimasa depan. Hampir semua lahan yang ada lebih banyak dibangun untuk keperluan perumahan, bisnis, serta perkantoran, sehingga keberadaan Ruang Terbuka Hijau (RTH) sangat minim ketersediaannya. Fungsi ruang terbuka hijau ini sangat banyak, diantaranya dapat memberikan ruang yang terbuka bagi masyarakat untuk melakukan aktivitas relaksasi dan rekreasi setelah kegiatan rutin keseharian. Keberlangsungan kearifan lokal akan tercermin dalam nilai-nilai yang berlaku dalam kelompok masyarakat tertentu (Ambalegin, 2019). Keberadaan Ruang terbuka hijau ini sangat diperlukan juga untuk menjaga resapan air, penataan taman, dan salah satunya juga untuk keperluan pemakaman warga yang lebih dikenal dengan Tempat Pemakaman Umum atau disingkat TPU.

Dalam peraturan hukum di Indonesia, tempat pemakaman diatur oleh Pemerintah Negara Republik Indonesia di bawah Departemen Dalam Negeri berdasarkan Peraturan Pemerintah Nomor 9 Tahun 1987 tentang Penyediaan dan Penggunaan Tanah Untuk Keperluan Tempat 
Pemakaman serta Keputusan Menteri Dalam Negeri Nomor 26 Tahun 1989 tentang Pedoman Pelaksanaan peraturan Pemerintah Nomor 9 Tahun 1987. Tempat pemakaman Umum (TPU) Muslim Al lkhlas Kelurahan Sungai Bangkong merupakan salah satu TPU terbesar yang ada di Pontianak. TPU ini memiliki lahan seluas kurang lebih $4 \mathrm{Ha}$, dengan lokasi berada di Kelurahan Sungai Bangkong kecamatan Pontianak Barat. Keberadaan TPU Sungai Bangkong yang berada di pusat kota menuntut adanya penataan yang lebih baik lagi, mengingat pemakaman ini akan mempengaruhi estetika ruang publik serta memberikan pengaruhnya kepada sosial dan lingkungan sekitarnya. Penataan kembali Tempat Pemakaman Umum (TPU) Muslim Al lkhlas Kelurahan Sungai Bangkong diharapkan bisa menjadikan kawasan ini menjadi lebih asri dan indah tanpa mengesampingkan fungsi makam sebagai Ruang Terbuka Hijau dan sebagai area resapan air.

Berdasarkan Permendagri No.1 Tahun 2007 Pemakaman merupakan salah satu jenis dari Ruang Terbuka Hijau (RTH), sebagaimana pernanfaatan utamanya sebagai kuburan dengan kegiatan didalamnya seperti berziarah namun diharapkan masih memiliki fungsi lain, misalnya sebagai taman kota sekaligus sebagai pusat orientasi kawasan yang bemilai religious. Menurut Budhiharjo dan Hardjohubojo (1993), Keberadaan TPU harus ada dan tetap dipertahankan di tengah-tengah kehidupan kota metropolitan. Sebab, pemakaman merupakan komponen utama dalam siklus kehidupan kota, condition sine qua non, syarat mutlak yang tidak bisa ditawar-tawar. Di Kota Pontianak, lahan pemakaman yang tersedia merupakan wakaf dari masyarakat yang tinggal di dekat area pemakaman. Pengelolaan pemakaman di Kota Pontianak dibawahi oleh Dinas Kebersihan, Pertamanan dan Pemakaman, dan dinas tersebut melakukan suatu pengelolaan yang disesuaikan oleh peraturan daerah serta bertanggung jawab dalam mengurusi masyarakat yang meninggal tanpa adanya identitas. Pemakaman yang terletak di dalam sebuah kota menjadi aset penting yang dapat menaikan mutu atau kualitas dari Kota tersebut. Pemakaman merupakan sebuah Ruang Terbuka Hijau yang memberikan banyak keuntungan terutama bagi lingkungan sekitar tempat pemakaman tersebut berada. Jika melihat kondisi RTH pemakaman yang terdapat pada daerah di Kota Pontianak, maka kita akan melihat bahwa sebagian besar pemakaman tersebut kurang memiliki nilai estetika. Pada kenyataannya, pemakaman yang terdapat di daerah urban mempunyai fungsi khusus sebagai salah satu areal hijau dan resapan air dan dapat membantu mengurangi permasalahan seperti polusi udara yang dikeluarkan dari padatnya kendaraan bermotor di jalan raya dan bahaya banjir.

\section{METODE}

Menurut Indriana (2014), TPU Muslim memerlukan desain khusus dalam penataan pemakaman. Ada beberapa komponen yang memiliki kriteria yang harus diperhatikan dalam penataan ini. Seperti petak makam dengan standar ukuran 1 x 2 meter dengan jarak antar makam 0.5 meter serta kedalaman galian makam 1.5 meter, standarisasi kijing yang tidak permanen dan didesain hanya menggunakan hamparan rumput diatasnya, elemen vegetasi, pedestrian, tempat parkir dan kantor pengelola. Lebih lanjut Indriani (2014) menyebutkan bahwa TPU Muslim Al lkhlas Sungai Bangkong diarahkan pada pemakaman model tumpang dan diarahkan kepada pengelolaan RTH sehingga keseimbangan ekologis kota dapat terjaga. Permasalahan ini menjadi dasar dilakukannya PKM dengan merencanakan secara spesifik dan terperinci mengenai penataan dan perencanaan kawasan TPU Sungai Bangkong di Kota Pontianak, untuk mewadahi segala macam kegiatan rekreasi dan social serta lingkungan Daerah Resapan air dengan pengaturan tata letak atau pola makam, maupun akses dan sirkulasi dalam kawasan makam. Secara garis besar, kegiatan dimulai dengan pengukuran langsung di lapangan, mendata jumlah makam yang ada serta melakukan beberapa kali identifikasi dan konsultasi ke pengurus yayasan serta instansi pemerintah daerah yang terkait, dalam hal ini Dinas PUPR Kota Pontianak. Selanjutnya melakukan identifikasi penyelesaian masalah (Nurjayadi dkk, 2020) dengan mengkaji kawasan berupa sirkulasi jalan masuk, akses jalan ke makam, penghijauan, ketinggian kontur muka air pasang serta penerangan kawasan. Kemudian menghasilkan konsep tentang perencanaan dan perancangan kawasan, dan membuat desain kawasan berdasarkan konsep dan 
melakukan kegiatan perancangan dengan menghasilkan output berupa bentuk visualisasi desain kawasan makam dalam gambar pradesain.

Perencanaan meliputi rumusan program ruang yang dibutuhkan, konsep arsitektur dan lingkungan, gambar pra desain dan gambar detail teknis beserta rencana anggaran dan biaya (RAB) pembangunan. Untuk mewujudkan hal tersebut maka pelibatan masyarakat sebagai pelaku dan pemakai (Nurjayadi dkk, 2020) diharapkan menghasilkan kolaborasi akan keinginan masyarakat tentang penataan kawasan TPU Sungai Bangkong. Adapun metode kegiatan yang dilakukan adalah :

a. Mengumpulkan dan mempersiapkan data-data awal perencanaan dengan survey langsung ke lapangan

b. Analisis data dan diskusi tim

c. Merumuskan konsep perencanaan dan perancangan kawasan

d. Mengajukan usulan perencanaan dan rancangan berupa gambar pradesain

e. Melakukan evaluasi usulan perencanaan dan penataan kawasan

f. Menyiapkan desain (perancangan) yang sesuai dengan konsep

\section{HASIL DAN PEMBAHASAN}

Menurut Sadyohutomo (2008), Konsep manajemen atau pengelolaan pemakaman mengandung pengertian bahwa dalam perspektif keruangan (tanah, lahan), pemakarnan dapat dipandang sebagai potensi dan aset untuk menggali dan meningkatkan pendapatan daerah. Tahap awal yang dilakukan kegiatan ini adalah membuat peta kawasan dengan melakukan tracking berdasarkan foto citra satelit yang di ambil dari aplikasi googleearth. Citra satelit ini kemudian dikonversikan ke dalam format gambar CAD melalui aplikasi AutoCAD.

Pengambilan data lainnya adalah dengan melakukan pengambilan foto secara langsung melalui pemotretan kawasan serta melakukan pengukuran secara manual pada jalan masuk, batas lahan dan bangunan yang ada. Lokasi memiliki beberapa vegetasi yang berpotensi untuk dipertahankan sebagai bagian dari penghijauan kawasan. Masih banyak semak belukar yang ada dikawasan pemakaman dan menjadi salah satu masalah yang harus di selesaikan agar kawasan makam nantinya terlihat asri.
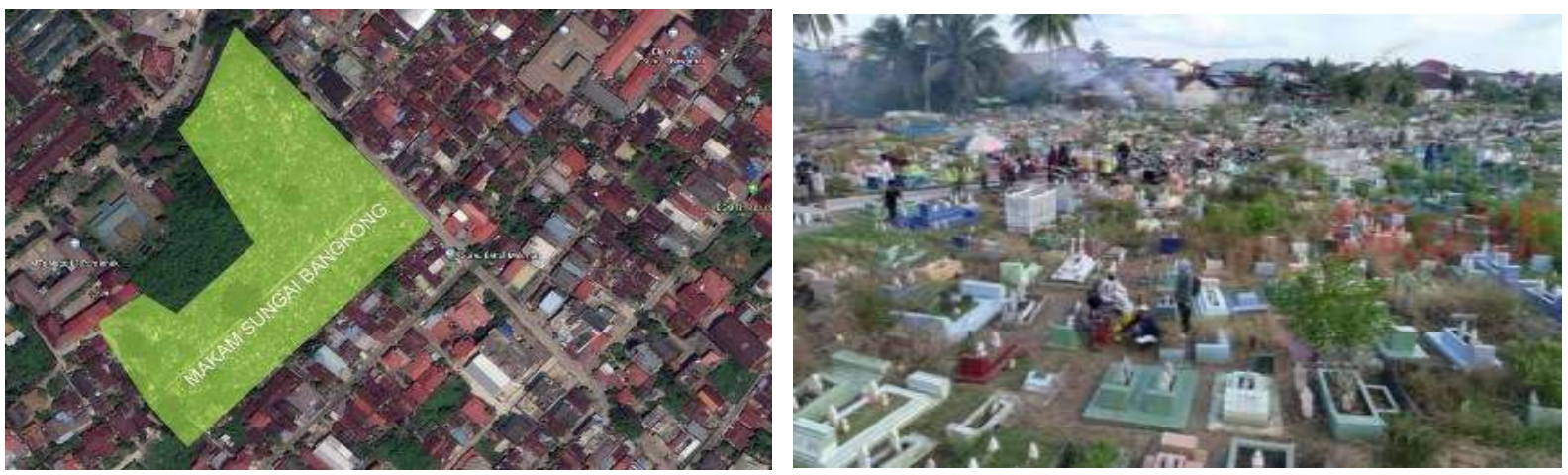

Gambar 1. Citra Satelit dan Kondisi Kawasan TPU Sungai Bangkong Pontianak

\section{Konsep Perencanaan dan Penataan Kawasan}

Menurut Hutauruk (2003), komponen penataan kawasan TPU terdiri dari petak makam, elemen vegetasi, jalur pejalan kaki, jalur kendaraan dan tempat parkir, plaza dan ruang terbuka, gedung pengelola TPU, elemen penanda, lampu penerangan, tempat duduk, gerbang, pagar, dan jaringan utilitas. Permen PU No. 5 Tahun 2008 tentang Pedoman Penyediaan dan Pemanfaatan Ruang Terbuka Hijau di Kawasan Perkotaan menyebutkan bahwa Penyediaan ruang terbuka hijau pada areal pemakaman disamping memiliki fungsi utama sebagai tempat penguburan jenazah juga memiliki fungsi ekologis yaitu sebagai daerah resapan air, tempat 
pertumbuhan berbagai jenis vegetasi, pencipta iklim mikro serta tempat hidup burung serta fungsi sosial masyarakat disekitar seperti beristirahat dan sebagai sumber pendapatan.

\section{Sirkulasi Kawasan}

Konsep sirkulasi kawasan merupakan hal yang harus di tata, diantaranya adalah sirkulasi kendaraan dan pengunjung makam. Sirkulasi jalan masuk ke dalam kawasan makam di buat mudah dan efisien dengan tidak meninggalkan konsep keindahan. Konsep Sirkulasi ini meliputi penataan akses jalan masuk utama kawasan yang diperuntukkan bagi pejalan kaki (pengunjung makam) dan kendaraan tertentu (mobil jenazah dan roda dua). Jalan masuk utama di buat lebar agar mobil jenazah bisa masuk ke area makam dan memudahkan pengunjung menghantar jenazah sedekat mungkin dengan akses lubang makam yang di buat. Akses jalan ini di perkeras dengan cor beton dan di lapisi batu alam jenis andesit agar akses ini kelihatan indah dan asri. Pemasangan batu alam pada jalan akses ini dimaksudkan agar jalan masuk makam terlihat bagus sepereti halnya taman kota. Konsep taman dihadirkan di kawasan agar kesan makam yang awalnya menyeramkan menjadi sesuatu yang menarik. Hal ini akan menambah daya tarik warga untuk sering berkunjung ke makam dalam memenuhi aktivitas sosial, religi dan rekreasi.

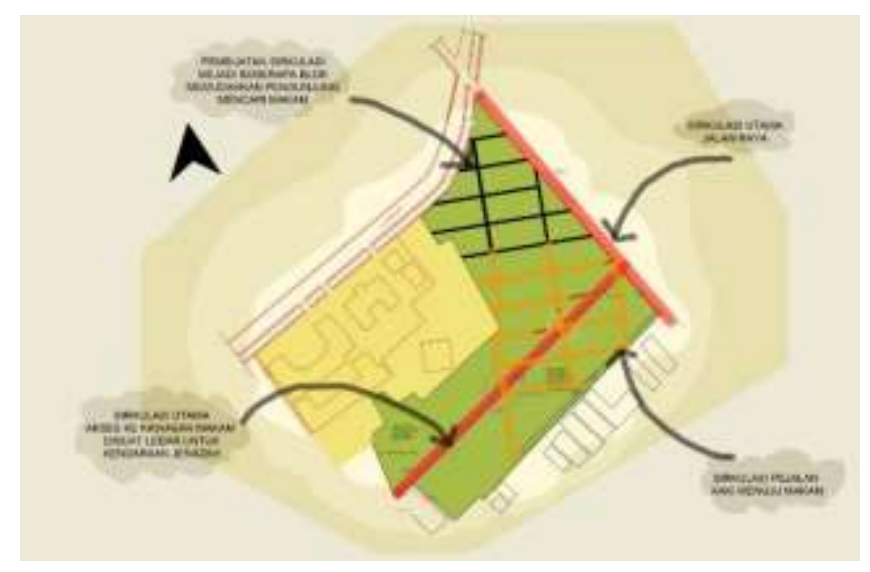

Gambar 2. Konsep sirkulasi Kawasan TPU Muslim Al lkhlas Kelurahan Sungai Bangkong Pontianak

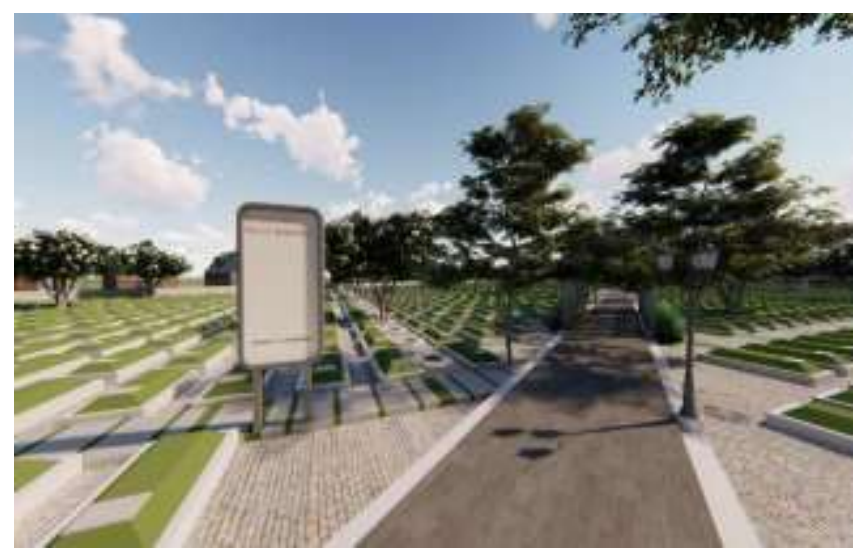

Gambar 3. Konsep Jalan Kawasan TPU Muslim Al lkhlas Kelurahan Sungai Bangkong Pontianak

\section{Penerangan Kawasan}

Penataan penerangan kawasan diperlukan untuk memberikan kesan makam terlihat indah dan tidak menyeramkan. Makam identik dengan sesuatu yang menyeramkan akan berubah menarik jika penataan penerangan dilakukan di sekitar kawasan. Penempatan penerangan kawasan makam ini dipasang di sepanjang jalan masuk utama dan sekitar jalan umum yang menuju makam. Lampu taman yang dipilih harus menyesuaikan konsep keindahan dan fungsi yang baik. 


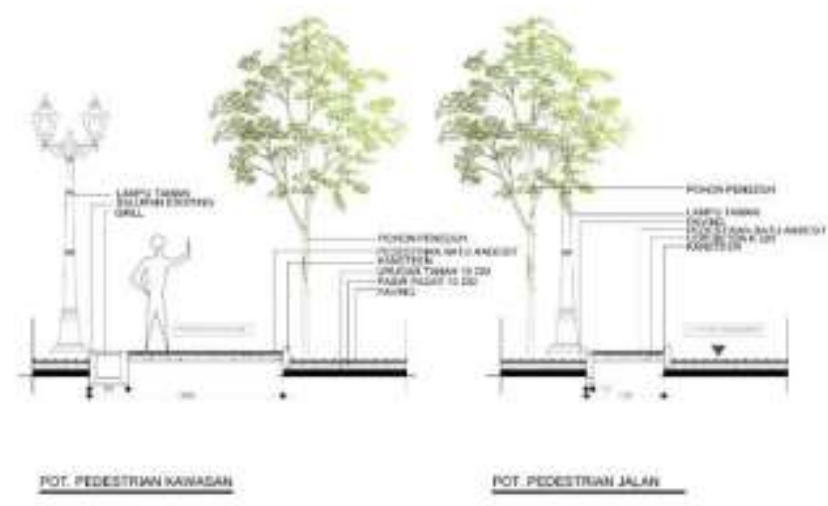

Gambar 4. Konsep Penerangan Kawasan TPU Muslim Al lkhlas Kelurahan Sungai Bangkong Pontianak

Untuk lampu jalan utama di sisi makam, di letakkan jenis lampu penerangan jalan. Sedangkan lampu yang digunakan untuk akses masuk ke makam dipilh jenis lampu taman yang memiliki nuansa klasik berbahan besi tempa. Ketinggian lampu ini disesuikan dengan kebutuhan dan harus aman dari pencurian atau kerusakkan yang disengaja oleh oknum pengunjung.

\section{Vegetasi Kawasan}

Ruang terbuka kota pada dasarnya adalah ruang kota yang tidak terbangun, yang berfungsi sebagai penunjang tuntutan akan kenyamanan, keamanan, peningkatan kualitas lingkungan dan pelestarian alam yang terdiri dari ruang linier atau koridor dan ruang pulau atau oasis sebagai tempat perhentian (Hakim, 2003). Penataan vegetasi di kawasan makam bertujuan untuk menciptakan suasana asri di kawasan tersebut. Pohon yang mengganggu serta semak belukar yang ada di ganti dengan pohon yang berbunga seperti pohon kamboja yang memiliki bunga berbau harum. hal ini bisa menambah suasana sakral di areal makam serta ketika saat berbunga, kawasan akan tampak indah. Pohon besar sebagai pelindung dan peneduh di area kawasan perlu di jaga dan dipertahankan.

Menurut Indriana (2014), perlu membuat pola tanaman yang teratur pada kawasan pemakaman sehingga kelihatan rapi dan teratur. Di daerah pejalan kaki diperlukan ruang yang bebas dari juntaian ranting dan dahan pohon sekitar 2,5 $\mathrm{m}$ dari permukaan tanah.Penggunaan rumput untuk area makam yang bertujuan untuk menciptakan suasana asri perlu dipertimbangkan dari sisi perawatannya. Hal ini jangan sampai menciptakan semak belukar baru jika tidak terawat dengan baik. Untuk itu perlu ditata dengan mempertimbangkan bahan penutup tanah yang efisien dalam pelaksanaan serta perawatan. Jenis paving blok sangat baik sekali digunakan untuk menutup sebagian kawasan makam dan di kombinasikan dengan rumput jenis gajah mini yang mudah dalam perawatannya.

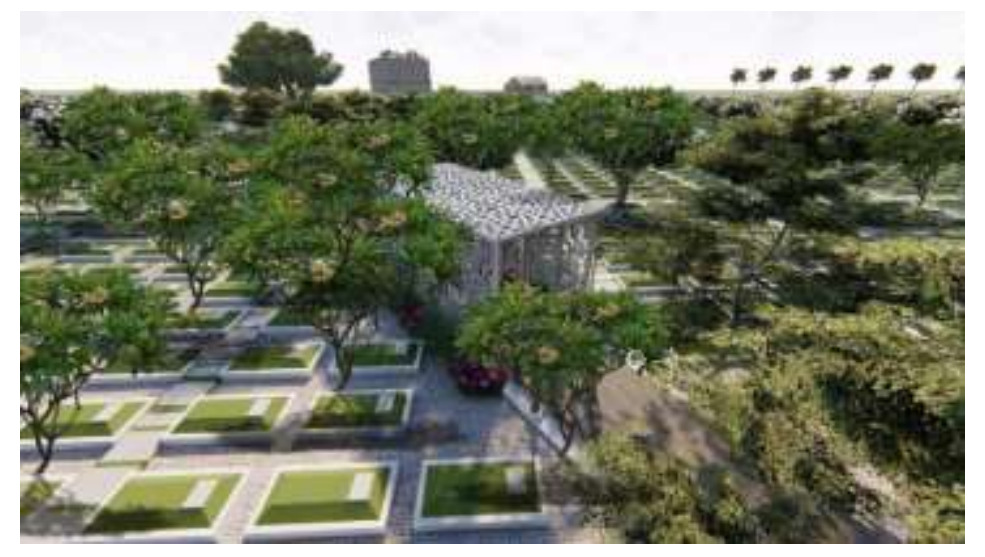

Gambar 5. Konsep vegetasi kawasan TPU Muslim Al lkhlas Kelurahan Sungai Bangkong Pontianak 


\section{Penataan Makam}

Hal penting dalam disain TPU sungai Bangkong ini adalah penataan makam. Berdasarkan Permen Pekerjaan Umum No. 5 tahun 2008 tentang Pedoman Penyediaan dan Pemanfaatan Ruang Terbuka Hijau di Kawasan Perkotaan, ketentuan pemakaman sebagai berikut:

a. ukuran makam $1 \mathrm{~m} \times 2 \mathrm{~m}$;

b. jarak antar makam satu dengan lainnya minimal 0,5 m;

c. tiap makam tidak diperkenankan dilakukan penembokan/perkerasan; pemakaman dibagi dalam beberapa blok, luas dan jumlah blok disesuaikan kondisi pemakaman setempat;

d. batas antar blok pemakaman berupa pedestrian lebar 150-200 cm dengan deretan pohon pelindung disalah satu sisinya;

e. batas terluar pemakaman berupa pagar tanaman atau kombinasi antara pagar buatan dengan pagar tanaman, atau dengan pohon pelindung;

f. ruang hijau pemakaman termasuk pemakaman tanpa perkerasan minimal $70 \%$ dari total area pemakaman dengan tingkat liputan vegetasi $80 \%$ dari luas ruang hijaunya. Pemilihan vegetasi di pemakaman disamping sebagai peneduh juga untuk meningkatkan peran ekologis pemakaman termasuk habitat burung serta keindahan.

Makam yang dimaksudkan adalah tempat penanda kuburan bagi masing masing jenazah yang dimakamkan di tempat yang sudah disediakan. Perletakkan masing masing makam ini sangat semrawut dan tak tertata dengan baik. Pendataan sejak awal jumlah dan nama makam harus dilakukan dengan baik, agar data makam yang ada bisa membantu pengunjung mudah dalam mencari makam yang akan di ziarahi.

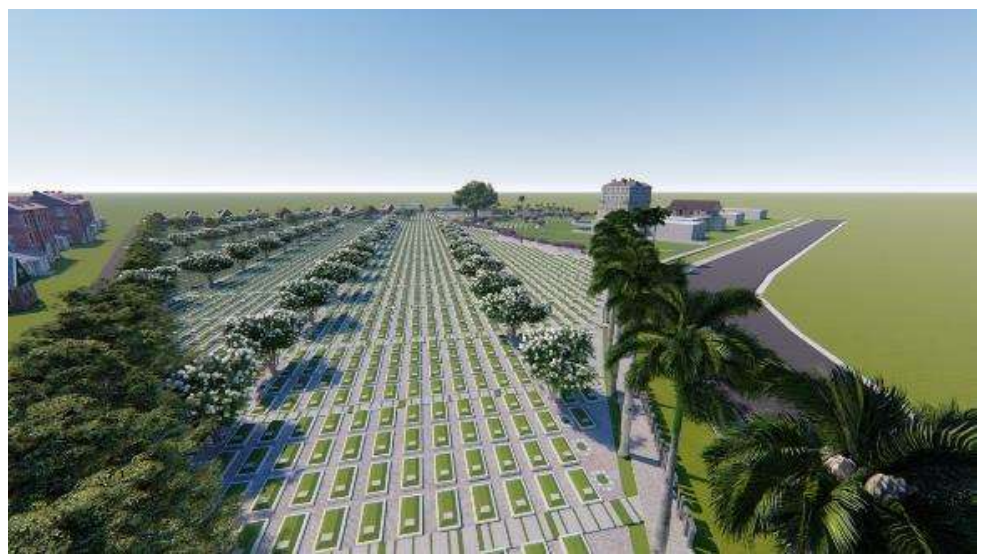

Gambar 6. Konsep penataan makam dan desain makam TPU Muslim Al lkhlas Kelurahan Sungai Bangkong Pontianak

Menurut Indriana (2014), petak makam dengan standar ukuran 1 x 2 meter dengan jarak antar makam 0.5 meter serta kedalaman galian makam 1.5 meter, standarisasi kijing yang tidak permanen dan didesain hanya menggunakan hamparan rumput diatasnya, elemen vegetasi, pedestrian, tempat parkir dan kantor pengelola. Desain makam atau tambak kuburan ini dibuat simpel, murah dan informatif. Semua makam dibuat dengan seragam dan dibagi dalam beberapa blok. hal ini agar memudahkan pengunjung untuk mencari makam yang akan di kunjungi. Papan informasi berupa peta letak makam dibuat dan ditempatkan sesuai dengan blok area makam. Ketika pengunjung akan berziarah, maka mereka tinggal mencari data tersebut untuk mengetahui posisi letak makam yang mereka cari. Nama untuk masing masing makam harus dibuat jelas dan tahan terhadap cuaca. Penggunaan material berjenis batu marmer untuk penamaan makam ini sangat bagus untuk dilakukan dengan mengukir nama makam sesuai data base yang dibuat nantinya. 


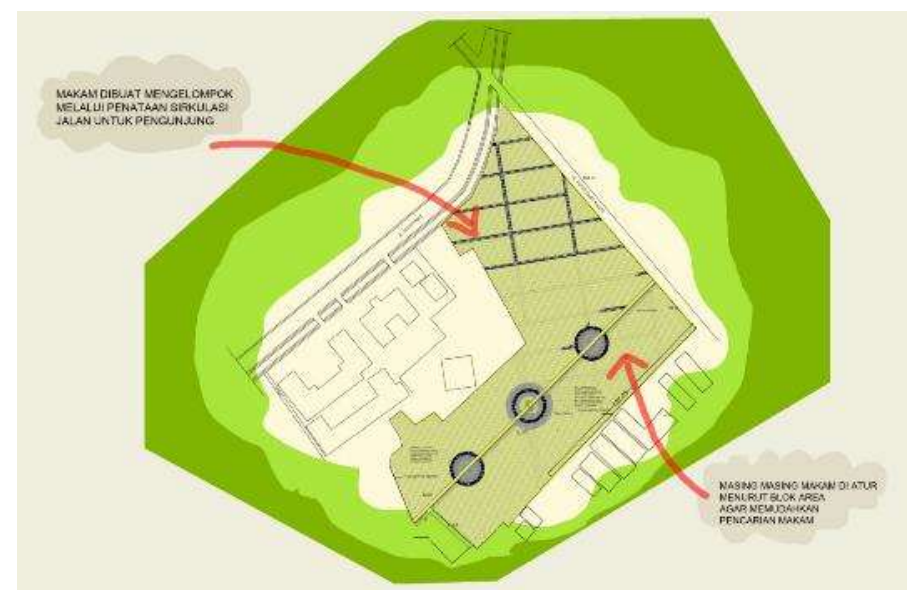

Gambar 7. Konsep Tata letak makam TPU Muslim Al lkhlas Kelurahan Sungai Bangkong Pontianak

\section{Drainase Kawasan}

Menurut Indriana (2014), kawasan TPU Sunagi Bangkok selalu mengalami genangan air pada saat hujan karena tidak adanya parit-parit/selokan kecil antar blok sebagai jalur yang dapat mengalirkan air hujan. Letak geografis Kota Pontianak yang dilalui oleh Sungai Kapuas serta topografinya yang sebagian besar wilayahnya merupakan lahan yang datar dengan kemiringan lahan 0 - $2 \%$. Perencanaan drainase yang dapat mengalirkan air yang menggenangi kawasan untuk dialirkan ke drainase kota, parit jalan Alianyang.

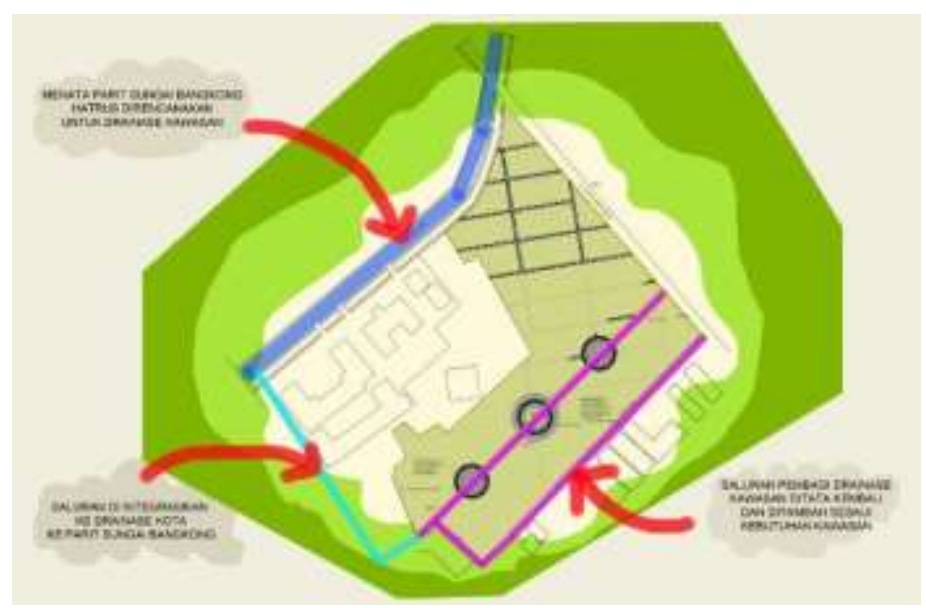

Gambar 8. Konsep Drainase kawasan TPU Muslim Al lkhlas Kelurahan Sungai Bangkong Pontianak

\section{Fasade Kawasan}

Harani dan Motic (2017) menyampaikan bahwa sebuah kawasan di area perkotaaan ya dengan fungsi sebagai koridor jalan diharapkan memiliki karakter tersendiri agar memiliki citra untuk dikenalkan ke masyarakat sebagai karakter kawasannya. Menurut Harani dan Motic (2017), tampilan fasade bangunan pada sebuah kawasan memiliki peran penting untuk membangun sebuah karakter visual kawasan yang dapat menggambarkan citra kawasan itu sendiri. Sebuah karakter akan memudahkan orang untuk mengenali kawasan itu sendiri. Oleh karena itu, Menurut Sudarwani dan Ekaputra (2013), Kawasan membutuhkan elemen-elemen penguat fasad kawasan berupa Circulation and parking, Open space, Pedestrian ways, Activity support, Signage, dan Preservtion. Oleh karena itu, Lingkungan kawasan TPU Muslim Al lkhlas Kelurahan Sungai Bangkong Pontianak membutuhkan disain yang terdiri dari elemen-elemen fix 
feature (bangunan, lantai, dinding, lapangan, trotoar, dll.). Selain itu, diperlukan juga elemenelemen semi fix feature (furnishing, interior, eksterior, seperti tiang lampu, perabot jalan, tempat duduk, pkl, dll), dan elemen-elemen non fix feature (manusia dengan aktivitas serta perilakunya).

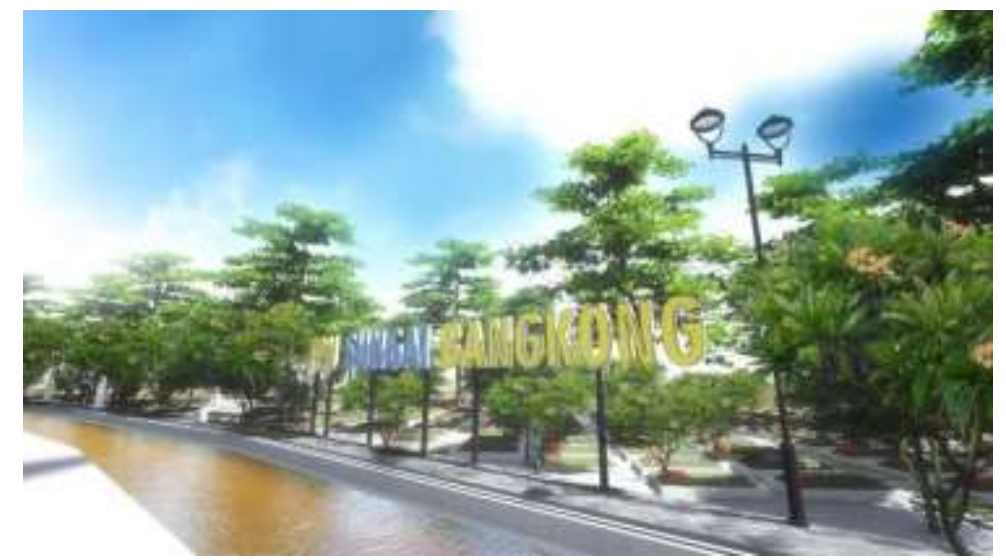

Gambar 9. Konsep fasad dari sisi parit Jalan Alianyang di kawasan TPU Muslim Al lkhlas Kelurahan Sungai Bangkong Pontianak

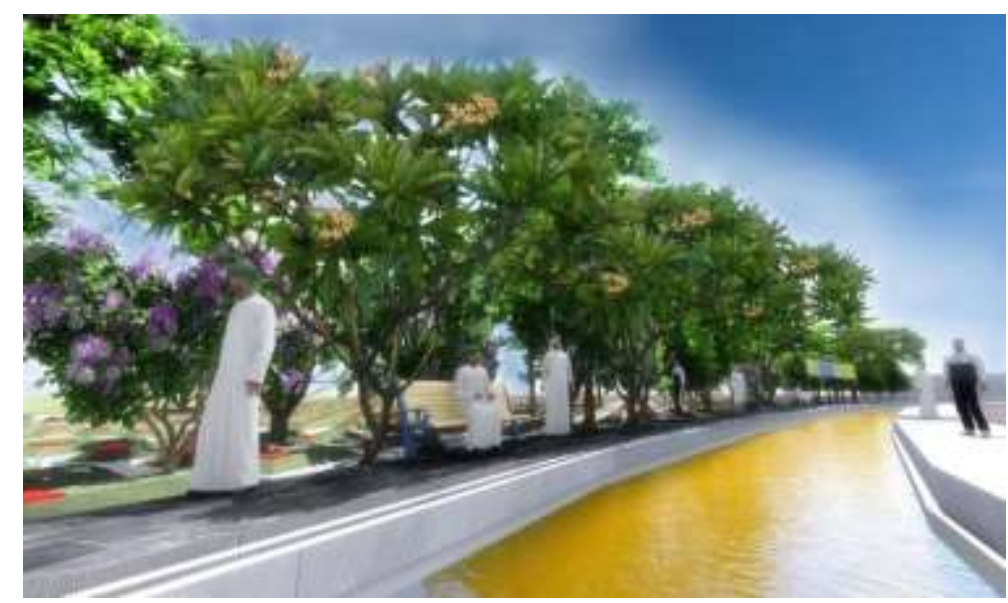

Gambar 10. Konsep fasad kawasan sepanjang parit Jalan Alianyang di Kawasan TPU Muslim Al lkhlas Kelurahan Sungai Bangkong Pontianak

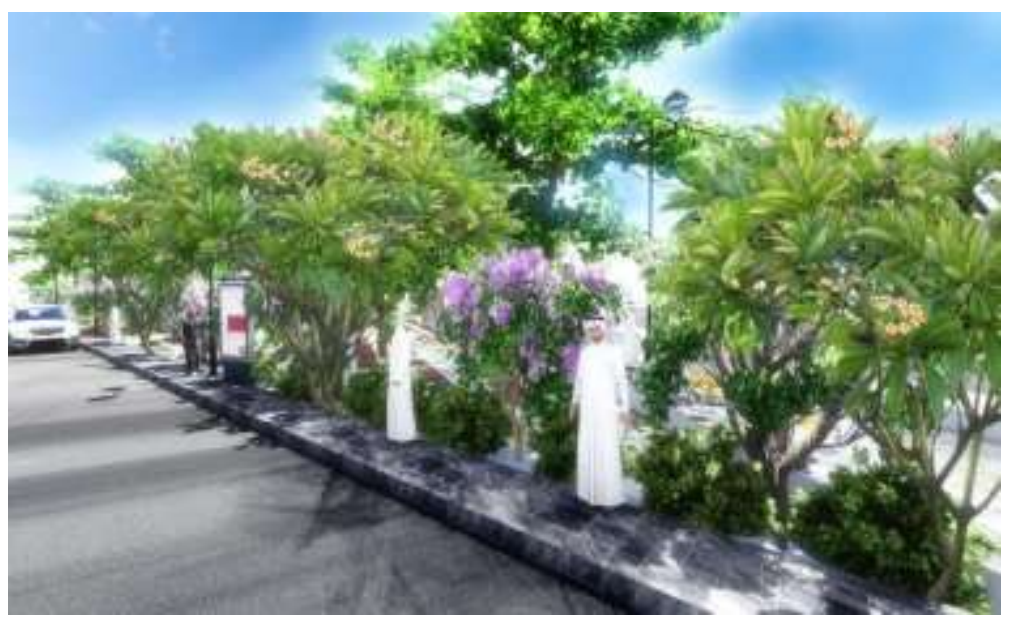

Gambar 11. Konsep fasad kawasan sepanjang jalan utama di TPU Muslim Al lkhlas Kelurahan Sungai Bangkong Pontianak 


\section{KESIMPULAN}

Penataan Kawasan TPU Sungai Bangkong Pontianak dimaksudkan mengembalikan fungsi ekologis makam sebagai daerah resapan air, tempat pertumbuhan berbagai jenis vegetasi, pencipta iklim mikro serta tempat hidup burung serta fungsi sosial masyarakat disekitar. Sirkulasi jalan masuk ke dalam kawasan makam dibuat untuk kemudahan akses dan efisien dengan tidak meninggalkan konsep keindahan. Penataan makan mengacu pada Peraturan Menteri Pekerjaan Umum No. 5 tahun 2008. Desain makam atau tambak kuburan ini dibuat simpel, murah dan informatif dengan keragaman bentuk berdasarkan blok. Penataan penerangan di kawasan ini diperlukan untuk memberikan kesan makam terlihat indah dan tidak menyeramkan. Konsep taman dihadirkan di kawasan agar kesan makam yang awalnya menyeramkan menjadi sesuatu yang menarik. Penataan dan pemilihan jenis vegetasi di kawasan makam dilakukan untuk menciptakan suasana asri di kawasan tersebut.

Perencanaan detail direkomendasikan untuk dilakukan dari usulan disain Kegiatan PKM ini. Implementasi yang berhubungan dengan perencanaan ini perlu memperhatikan efektivitas pelaksanaan dan melihat perkembangan masa depan berkaitan dengan pembangunan fisik kawasan TPU Sungai Bangkong. Perencanaan dan kajian secara teknis dan sosial yang matang maka diharapkan dapat hasil perencanaan kawasan makam TPU Sungai Bangkong yang disampaikan dalam Peraturan Menteri Pekerjaan Umum No. 5 tahun 2008. Perencanaan matang menjadi bagian dari perwujudan peduli untuk mengembalikan lingkungan kawasan makam menjadi fungsi sosial dan rekreatif sehingga nantinya kawasan ini akan lebih tertata dengan rapi dan asri.

\section{UCAPAN TERIMA KASIH}

Artikel ilmiah ini disusun dari laporan Hasil Program Pengabdian Kepada Masyarakat yang didanai dari DIPA Fakultas Teknik Universitas Tanjungpura Tahun Anggaran 2019. Ucapan terimakasih disampaikan kepada Civitas Akademika Fakultas Teknik Universitas Tanjungpura, khususnya rekan-rekan dosen di Jurusan Arsitektur.

\section{DAFTAR PUSTAKA}

Ambalegin; Tomi Arianto; Zefri Azharman. (2019). Kampung Tua Nongsa Sebagai Tujuan Wisata Berbasis Kearifan Lokal Budaya Melayu Batam. DINAMISIA - Jurnal Pengabdian Kepada Masyarakat Vol. 3, Special Issue Juni 2019, Hal. 67-75

Budihardjo, Eko; Sudanti Hardjohubojo. (1993). Kota Berwawasan Lingkungan. Penerbit Alumni. Bandung

Hakim, Utomo A. (2003). Komponen Perancangan Arsitektur Lansekap, Prinsip - Unsur dan Aplikasi Disain. Bumi Aksara. Jakarta

Harani, Arnis Rochma; Ken Motic. (2017). Pengaruh Fasade Bangunan Terhadap Karakter Visual Kawasan (Studi Kasus: Pecinan Semarang, Malaysia dan Singapura). Jurnal Pengembangan Kota (2017) Volume 5 No. 1 (1-8) DOI: 10.14710/jpk.5.1.1-8

Hutauruk, Tona. (2003). Prinsip-Prinsip Penataan Tempat Pemakaman Umum (FPU) yang Dapat Digunakan Sebagai Ruang Terbuka Hijau di DKI Jakarta. Tugas Akhir Jurusan Teknik Planologi ITB. Bandung

Indriana, Dewi Ria. (2014). Arahan Konsep Pengelolaan Dan Pengembangan Tempat Pemakaman Umum Muslim: Studi Kasus TPU Muslim Al-Ikhlas Sungai Bangkong \& TPU Muslim Danau Sentarum Kecamatan Pontianak Kota. Tesis pada Program Magister Teknik Sipil Fakultas Teknik Universitas Tanjungpura. Pontianak

Kementerian Dalam Negeri RI. (1988). Instruksi Menteri Dalam Negeri Nomor 14 Tahun 1988 Tentang Penataan Ruang Terbuka Hijau Di Wilayah Perkotaan. Kementerian Dalam Negeri RI. Jakarta 
Kementerian Dalam Negeri RI. (1989). Keputusan Menteri Dalam Negeri Nomor 26 Tahun 1989 tentang Pedoman Pelaksanaan Peraturan Pemerintah No. 9 Tahun 1987 tentang Penyediaan dan Penggunaan Tanah untuk Keperluan TempatPemakaman. Kementerian Dalam Negeri RI. Jakarta

Kementerian Dalam Negeri RI. (2007). Peraturan Menteri Dalam Negeri Nomor 1 Tahun 2007 tentang Pemakaman Merupakan Salah Satu Jenis dari Ruang Terbuka Hijau (RTH). Kementerian Dalam Negeri RI. Jakarta

Kementerian Pekerjaan Umum RI. (2008). Peraturan Menteri Pekerjaan Umum No. 5 Tahun 2008 tentang Pedoman Penyediaan dan Pemanfaatan Ruang Terbuka Hijau di Kawasan Perkotaan. Kementerian Pekerjaan Umum RI. Jakarta

Nurjayadi; Torkis Nasution; Herwin; Khusaeri Andesa. (2020). Peningkatan Pelayanan Terhadap Masyarakat Melalui Implementasi Smart Village Pada Desa Rimba Makmur. DINAMISIA: Jurnal Pengabdian Kepada Masyarakat Vol. 4, No. 1 Maret 2020, Hal. 140-151, DOI: https://doi.org/10.31849/dinamisia.v4i1.3224

Sadyohutomo, Mulyono. (2008). Manajemen Kota dan Wilayah. Bumi Aksara. Jakarta

Sudarwani, Margareta Maria; Yohanes Dicky Ekaputra. (2013). Gang Baru Sebagai Pembentuk Identitas Kawasan Pecinan Kota Semarang. Laporan Penelitian Pada Jurusan Arsitektur Fakultas Teknik Universitas Pandanaran. Lembaga Penelitian Dan Pengabdian Kepada Masyarakat (LPPM) Universitas Pandanaran. Semarang 